\title{
CYTOLOGICAL AND HISTOPATHOLOGICAL CORRELATION OF THYROID NODULES- A PROSPECTIVE STUDY
}

\author{
Lakshmi Khandige Sharma1, Pradeep Rudramurthy², Veni Upputuru ${ }^{3}$
}

${ }^{1}$ Associate Professor, Department of Pathology, Sanjay Gandhi Institute of Trauma and Orthopaedics, Bengaluru, Karnataka, India. ${ }^{2}$ Associate Professor, Department of Pathology, Indira Gandhi Institute of Child Health, Bengaluru, Karnataka, India. ${ }^{3}$ Research Assistant, Department of Biochemistry, Sanjay Gandhi Institute of Trauma and Orthopaedics, Bengaluru, Karnataka, India.

ABSTRACT
BACKGROUND
Fine needle aspiration cytology (FNAC) has been the diagnostic procedure of choice for the initial screening of patients with
thyroid swellings, the main goal of which is to distinguish nodules that require surgery from those which do not, in order to avoid
unnecessary thyroidectomy. We wanted to determine the correlation between FNAC and histological diagnosis of solitary/multiple
thyroid nodules.

\section{MATERIALS AND METHODS}

A prospective study was conducted by cytological examination of all solitary/multiple thyroid nodules and its correlation with histopathological diagnosis at M. S. Ramaiah Medical College and Teaching Hospital.

\section{RESULTS}

Out of 175 aspirations made on solitary/multiple nodules of thyroid, cytological diagnosis of non-neoplastic lesions was made in $84.5 \%$ of cases. Diagnosis of neoplastic lesions was considered in $13.2 \%$ of cases which consisted of follicular neoplasm (78.5\%), Papillary carcinoma (8.6\%), Hurthle cell adenoma (4.3\%) and medullary carcinoma (4.3\%). Histopathological study revealed sensitivity of $75.8 \%$, specificity of $100 \%$ and accuracy of $90.54 \%$ in detecting neoplastic lesions.

\section{CONCLUSION}

FNAC is a simple, cost-effective and easily repeatable screening test for thyroid lesions. It can be recommended as a first line investigation in the management of thyroid nodules.

\section{KEY WORDS}

Thyroid Nodules, Cytology, Histopathology

HOW TO CITE THIS ARTICLE: Sharma LK, Rudramurthy P, Upputuru V. Cytological and histopathological correlation of thyroid nodules- a prospective study. J. Evolution Med. Dent. Sci. 2019;8(12):919-923, DOI: 10.14260/jemds/2019/204

\section{BACKGROUND}

Fine needle aspiration cytology (FNAC) is a diagnostic procedure by means of which cellular material is aspirated by a syringe and a fine needle under negative pressure. ${ }^{1}$ FNAC of thyroid for the diagnosis of thyroid cancers was first reported by Mortin and Ellis in $1930^{2}$. FNAC has been the diagnostic procedure of choice for initial screening of patients with thyroid swellings, the main goal of which is to distinguish nodules that require surgery from those which do not in order to avoid unnecessary thyroidectomy. ${ }^{3}$ FNAC is also valuable in metastatic disease, both to identify tumours in the thyroid and to diagnose distant metastasis of thyroid cancer.4,5 Various thyroid lesions are most often readily recognizable by their characteristic cellular patterns in smears of needle aspirates particularly by experienced cytologists. Among thyroid neoplasms, papillary carcinoma is usually proven to be least difficult malignant neoplasm to be diagnosed on FNAC. 6 The separation of a follicular adenoma and follicular carcinoma has invariably been unsuccessful at cytology and

'Financial or Other Competing Interest': None.

Submission 23-02-2019, Peer Review 15-03-2019,

Acceptance 18-03-2019, Published 25-03-2019.

Corresponding Author:

Dr. Pradeep Rudramurthy,

Indira Gandhi Institute of Child Health,

South Hospital Complex, Bangalore,

Karnataka, India.

E-mail:docpradi@gmail.com

DOI: $10.14260 /$ jemds $/ 2019 / 204$ these neoplasms are therefore grouped as follicular neoplasms by most cytological pioneers. ${ }^{7}$ Though published results claim a sensitivity of over $90 \%$, leading some of the authors to recommend FNAC as the initial test in the evaluation of any thyroid nodule.8,9 FNAC has some limitations and both false positive and false negative results occur. Moreover, the incidence of false negative diagnosis is difficult to ascertain as considerably less number of thyroid nodules with benign cytological findings undergo surgery. 10 The present study has attempted to assess correlation between FNAC and histopathological diagnosis of solitary/multiple nodules of thyroid.

\begin{abstract}
Aims and Objectives
To determine the correlation between FNAC and histological diagnosis of solitary/multiple thyroid nodules. To distinguish nodules that require surgery from those which do not in order to avoid unnecessary thyroidectomy.
\end{abstract}

\section{MATERIALS AND METHODS}

Material for this study was obtained on a prospective basis from detailed cytological study of solitary/multiple nodules of thyroid from patients presenting to the Department of Pathology at M. S. Ramaiah Medical College and teaching hospital over a period of 2 years. A total of 205 cases of thyroid aspirations were done during this period. All the subjects presenting with thyroid nodules above the age of 15 years were included in the study. All subjects presenting with diffuse thyroid swellings were excluded from the study. After obtaining informed and written consent, aspiration of thyroid 
was done. The patients were kept under observation after the procedure for 10-15 minutes. Fixed/ air dried smears were stained with haematoxylin and eosin, May Grunwald Giemsa stain. Histopathological specimens were processed by the standard paraffin processing and stained with haematoxylin and eosin, and special stains wherever required. Ethical committee clearance was taken by the institutional ethical committee.

\section{RESULTS}

175 fine needle aspirations were done over a period of 2 years and were cytologically studied. Out of these 175 aspirations, satisfactory cell sample for cytological evaluation was obtained in 171 aspirations. The remaining aspirations were scanty with haemorrhage and occasional cells rendering them unsatisfactory for cytological evaluation. Cytological diagnosis of non-neoplastic lesions was made in 148 (84.5\%) aspirations and neoplastic lesions were diagnosed in 23 (13.2\%) aspirations. (Table 1, 2, 3). Among these, 75 patients underwent surgical procedure. Histologically, 40 cases were diagnosed to be non-neoplastic lesions and the remaining 30 cases were neoplastic, which included 22 cases of follicular adenoma, 1 case of Hurthle cell adenoma, 2 cases of follicular carcinoma, 3 cases of papillary carcinoma, and 1 case of medullary carcinoma. (Table 4). These 75 cases were available for correlation with cytology. (Table 5). 75 cases out of 175 fine needle aspirations were diagnosed as colloid goitre. Out of these, 33 cases underwent thyroidectomy. A diagnosis of colloid goitre was made histologically in 29 cases. 1 case reported as follicular neoplasm by FNA and 1 case with unsatisfactory material on aspiration turned out to be colloid goitre on histopathology (Table 4, 5). 3 cases reported as benign follicular lesion and 1 case reported follicular as neoplasm turned out to be nodular hyperplastic goitre (Table 4,5). Cytologically, 26 cases were reported as colloid cyst, 6 patients underwent surgery, out of which 5 cases were found to correlate with cytological diagnosis. However, 1 case turned out to be papillary carcinoma with cystic change. 14 cases were diagnosed as thyroiditis on aspiration. 12 cases out of this were diagnosed as Hashimoto's thyroiditis (Table 4, 5). Patients with cytologically diagnosed granulomatous thyroiditis \& Riedel's thyroiditis were not available for follow up.

Cytological diagnosis of neoplastic lesions were made in 23 of 175 aspirations Follicular neoplasm was diagnosed in 18 cases by FNA. 16 cases out of these correlated with the histological diagnosis. The other 2 cases turned out to be follicular carcinoma. In addition, 5 cases which were reported as colloid goitre turned out to be follicular adenoma. Out of 4 aspirations which were reported as unsatisfactory, 2 underwent thyroidectomy. They were found to be colloid goitre in one case $\&$ follicular adenoma in the other.

Based on these findings, sensitivity, specificity, accuracy, positive predictive value and negative predictive value in diagnosing neoplastic lesions on FNAC was calculated using the following formulae-

Sensitivity:

True Positive x 100

True positive+ False Negative

Specificity:

True Negative $\mathrm{x} 100$

True negative+ False Positive

Accuracy: $\quad$ True positive + True Negative $\mathrm{x} 100$

True Positive + True Negative + False Positive +False Negative

Positive Predictive Value:

True Positive $\mathrm{x} 100$

True Positive + False Positive

Negative Predictive Value:

False Negative $\times 100$

True Positive + False Negative

In this study we had a sensitivity of $75.8 \%$, specificity of $100 \%$, accuracy of $90.54 \%$, and positive predictive value of $100 \%$ and negative predictive value of $24.1 \%$ in diagnosing neoplastic lesions on fine needle aspiration cytology. The results are as follows-

\begin{tabular}{|c|c|c|c|}
\hline Sl. No. & Lesions & Number & Percentage \\
\hline 1 & Non Neoplastic & 148 & 84.5 \\
\hline 2 & Neoplastic & 23 & 13.2 \\
\hline 3 & Unsatisfactory & 4 & 2.3 \\
\hline \multicolumn{2}{r|}{ Table 2. Incidence of Cytologically Diagnosed Neoplastic and Non-Neoplastic Lesions } \\
\hline
\end{tabular}

\begin{tabular}{|c|c|c|c|}
\hline Sl. No. & Lesions & Number & Percentage \\
\hline $\mathbf{1}$ & Colloid Goiter & 75 & 50.8 \\
\hline 2 & Benign Follicular Lesion & 29 & 19.6 \\
\hline 3 & Colloid Cyst & 26 & 17.6 \\
\hline 4 & Hashimoto's Thyroiditis & 12 & 8.1 \\
\hline
\end{tabular}




\begin{tabular}{|c|c|c|c|}
\hline 5 & Hurthle Cell Rich Lesion & 04 & 2.7 \\
\hline 6 & Granulomatous Thyroiditis & 01 & 0.6 \\
\hline 7 & Riedel's Thyroiditis & 01 & 0.6 \\
\hline \multicolumn{2}{|c|}{ Total } & $\mathbf{1 4 8}$ & $\mathbf{1 0 0 . 0}$ \\
\hline
\end{tabular}

\begin{tabular}{|c|c|c|c|}
\hline Sl. No. & Lesions & Number & Percentage \\
\hline 1 & Follicular Neoplasm & 18 & 78.5 \\
\hline 2 & Papillary Carcinoma & 02 & 8.6 \\
\hline 3 & Hurthle Cell Neoplasm & 02 & 4.3 \\
\hline 4 & Medullary Carcinoma & 01 & 4.3 \\
\hline 5 & Follicular Neoplasm Possibly Parathyroid Adenoma & 01 & 4.3 \\
\hline \multicolumn{2}{|c|}{ Total } & $\mathbf{2 3}$ & $\mathbf{1 0 0 . 0}$ \\
\hline
\end{tabular}

\begin{tabular}{|c|c|c|c|}
\hline Sl. No. & Lesions & Number & Percentage \\
\hline & Non-Neoplastic Lesions & 41.3 \\
\hline 1 & Colloid goiter & 31 & 5.3 \\
\hline 2 & Nodular Hyperplastic Goiter & 04 & 6.7 \\
\hline 3 & Colloid Cyst & 05 & 6.7 \\
\hline 4 & Hashimoto's Thyroiditis & 05 \\
\hline & Neoplastic Lesions & 29.3 \\
\hline 1 & Follicular Adenoma & 22 & 1.4 \\
\hline 3 & Hurthle Cell Adenoma & 01 & 1.4 \\
\hline 4 & Parathyroid Adenoma & 01 & 3.9 \\
\hline 5 & Papillary Carcinoma & 03 & 2.6 \\
\hline 6 & Follicular Carcinoma & 02 & 1.4 \\
\hline \multicolumn{2}{|c|}{ Tedullary Carcinoma } & 01 & $\mathbf{1 0 0 . 0}$ \\
\hline
\end{tabular}

\begin{tabular}{|c|c|c|c|}
\hline Lesion & $\begin{array}{c}\text { Histopathological } \\
\text { Diagnosis }\end{array}$ & Cases Correlated & (\%) Correlated \\
\hline \multicolumn{4}{|l|}{ Non-Neoplastic Lesions } \\
\hline Colloid Goiter & 31 & 29 & 93.5 \\
\hline Nodular Hyperplastic Goiter & 04 & 03 & 75.0 \\
\hline Colloid Cyst & 05 & 05 & 100.0 \\
\hline Hashimoto's Thyroiditis & 05 & 04 & 80.0 \\
\hline \multicolumn{4}{|l|}{ Neoplastic Lesions } \\
\hline Follicular Adenoma & 22 & 16 & 72.7 \\
\hline Hurthle Cell Adenoma & 01 & 01 & 100.0 \\
\hline Parathyroid Adenoma & 01 & 01 & 100.0 \\
\hline Papillary Carcinoma & 03 & 02 & 66.7 \\
\hline Follicular Carcinoma & 02 & 02 & 100.0 \\
\hline Medullary Carcinoma & 01 & 01 & 100.0 \\
\hline Total & 75 & 66 & 88.0 \\
\hline
\end{tabular}
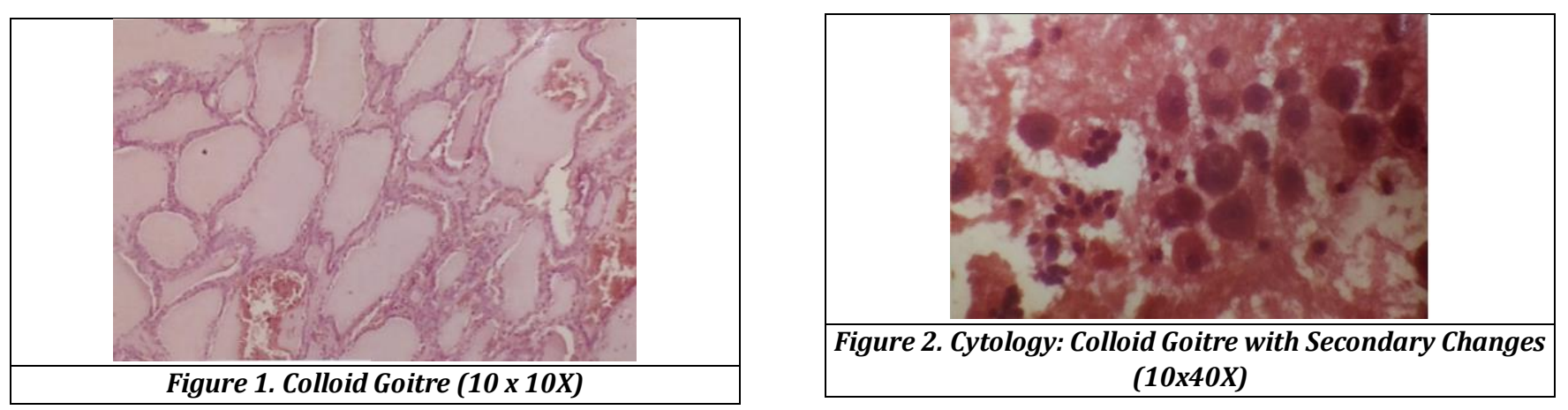

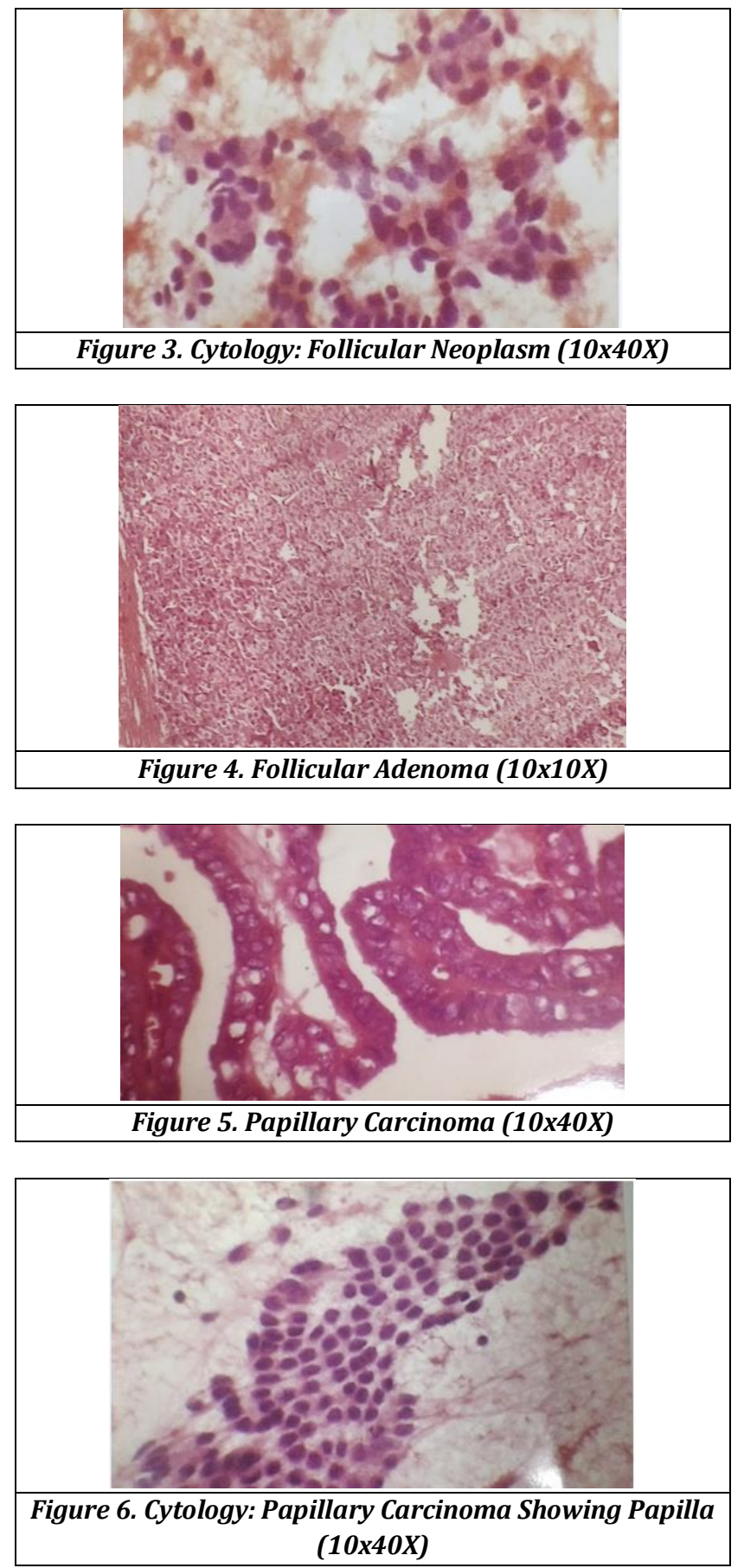

\section{DISCUSSION}

FNAC contributes significantly to the pre-operative investigation in patients with thyroid nodule but despite its well-recognized value, there are limitations to the technique. Because of simplicity, safety and diagnostic accuracy, FNAC has replaced open biopsy and has been accepted worldwide as a screening test to distinguish nodules that require surgery from that do not. In the present study, 175 patients with nodular thyroid swelling were subjected to FNAC. Cytological diagnosis of non-neoplastic lesions was made in 148 (84.6\%) aspirations and cytological diagnosis of neoplastic lesions was made in $23(13.1 \%)$ aspirations. In the remaining 4 aspirations, smears were unsatisfactory for evaluation. Tabaqchali et al ${ }^{11}$ in a similar study showed 160 nonneoplastic, 50 neoplastic and 3 unsatisfactory among 213 cases studied. Piromalli et al ${ }^{12}$ in a similar study showed 101 non neoplastic, 73 neoplastic and 42 unsatisfactory among
216 cases studied. Agarwal et $a^{13}$ showed 51 non neoplastic, 38 neoplastic and 11 unsatisfactory among 100 cases studied. In this study 75 cases of colloid goitre were reported, Alfroze et $\mathrm{al}^{14}$ reported 115 cases of colloid goitre. Mitra et al ${ }^{15}$ reported 24 cases of colloid goitre.

In the present study, we reported 18 cases of follicular neoplasm on cytology. Out of the 18 cases reported cytologically, 16 cases correlated with histological diagnosis. The other 2 cases turned out to be follicular carcinoma. In a similar study Piromalli et al ${ }^{12}$ reported 16 cases of follicular tumours on cytology and all of them turned out to be follicular adenomas at surgery.

In present study, 3 cases of papillary carcinoma were diagnosed on histology out of which 2 cases were picked up by FNAC. However, the other case presented as a cystic lesion was missed by FNAC. In a study conducted by Martelli et al 12 of the 36 patients with a malignant diagnosis, 27 had papillary carcinoma. Agarwal et al ${ }^{13}$ reported $66.7 \%$ cases of papillary carcinoma on FNAC. Mitra et al $^{15}$ diagnosed 10 cases of Papillary carcinoma, out of which 8 cases were diagnosed by cytology. Tabaqchali et al ${ }^{11}$ reported 34 cases of malignant thyroid tumours, out of which 18 cases were papillary carcinoma.

In the present study, we encountered $2.3 \%$ unsatisfactory smears. Piromalli et al 12 encountered a high rate of unsatisfactory specimen. In a study conducted by Agarwal et $\mathrm{al}^{13}$ incidence of unsatisfactory aspirates was $11 \%$. Tabaqchali et al ${ }^{11}$ also reported a very high rate of unsatisfactory smears amounting to $43.1 \%$ on the initial aspiration which was reduced to $32.2 \%$ with repeated aspiration. Alfroze et al ${ }^{14}$ reported $2.3 \%$ inadequate smears.

In our study, out of 6 cases reported as malignant on cytology, only 1 case was false negative, the rest 5 cases were confirmed to be malignant on histology. ( 2 cases of papillary carcinoma, 2 cases of follicular carcinoma and 1 case of medullary carcinoma)

In the present study out of 75 cases, false negative cases were $9.3 \%$. In a study conducted by Lowhangen et $\mathrm{al}^{16}$ among 412 cases $2.2 \%$ were False negative. In a study conducted by Ramaciotti et al ${ }^{17}$ among 126 cases $6.4 \%$ were False negative. In a study conducted by Silverman et al ${ }^{18}$ out of 60 cases $2.3 \%$ were False negative. In a study conducted by Altavilla et al ${ }^{19}$ out of 257 cases $3.1 \%$ were false negative and study by Piromalli et al ${ }^{12}$ showed $2.9 \%$ false negative results out of 216 cases studied.

In this study out of 75 cases false positive were reported. In a study conducted by Lowhangen et al ${ }^{16}$ among 412 cases $0.0 \%$ were False positive. In a study conducted by Ramaciotti et al ${ }^{16}$ among 126 cases, $3.2 \%$ were False positive. In a study conducted by Silverman et al ${ }^{17}$ out of 60 cases $3.2 \%$ were False positive. In a study conducted by Altavilla et al ${ }^{19}$ out of 257 cases, $0.0 \%$ were False positive. In a study conducted by Piromalli et al ${ }^{12}$ out of 216 cases $5.5 \%$ were False positive.

In the present study out of 75 cases sensitivity, specificity and accuracy of FNAC in thyroid lesions was $75.8 \%, 100 \%$ and $90.54 \%$ respectively. In a study conducted by Lowhangen et al ${ }^{16}$ among 412 cases sensitivity, specificity and accuracy of FNAC in thyroid lesions was $87.5 \%, 100 \%$ and $96.9 \%$ respectively. In a study conducted by Ramaciotti et al ${ }^{17}$ among 126 cases, sensitivity, specificity and accuracy of FNAC in thyroid lesions was $61.9 \%, 95.2 \%$ and $88.5 \%$ respectively. In a study conducted by Silverman et al ${ }^{18}$ out of 60 cases 
sensitivity, specificity and accuracy of FNAC in thyroid lesions was $93.0 \%, 96.5 \%$ and $94 \%$ respectively. In a study conducted by Altavilla et al ${ }^{19}$ out of 257 cases sensitivity, specificity and accuracy of FNAC in thyroid lesions was $71.4 \%, 100 \%$ and $95.1 \%$ respectively. In a study conducted by Agarwal et al ${ }^{13}$ out of 100 cases sensitivity, specificity and accuracy of FNAC in thyroid lesions was $76.5 \%, 95.9 \%$ and $90.9 \%$ respectively.

\section{CONCLUSION}

FNAC has the highest degree of accuracy in selecting patients for surgery on grounds of malignancy. FNAC is a simple, costeffective and easily repeatable screening test for thyroid lesions. It can be recommended as a first line investigation in the management of thyroid nodules.

\section{REFERENCES}

[1] Bibbo M. Comprehensive cytopathology. 2nd edn. Philadelphia: WB Saunders 1967: p. 673-701.

[2] Martin HE, Ellis EB. Biopsy by needle puncture and aspiration. Ann Surg 1930;92(2):169-81.

[3] Michelow PM, Leiman G. Metastasis to the thyroid gland: diagnosis by aspiration cytology. Diagn Cytopathol 1995;13(3):209-13.

[4] Smith SA, Gharib H, Goellner JR. Fine needle aspiration. Usefulness for diagnosis and management of metastatic carcinoma to the thyroid. Arch Intern Med 1987;147(2):311-2.

[5] Watts MS, Sewell CW. Carcinomatous involvement of the thyroid presenting as subacute thyroiditis. Am J Med Sci 1988;296(2):126-8.

[6] Kini S, Miller JM, Hamburger JI, et al. The cytopathology of papillary carcinoma of the thyroid by fine needle aspiration. Acta Cytol 1980;24(6):511-21.

[7] Goellner JR, Gharib H, Grant CS, et al. Fine needle aspiration cytology of the thyroid, 1980 to 1986 . Acta Cytol 1987;31(5):587-90.

[8] Akerman M, Tennvall J, Biorklund A, et al. Sensitivity and specificity of fine needle aspiration cytology in the diagnosis of tumours of the thyroid gland. Acta Cytol (Baltimore) 1985;29(5):850-5.
[9] Geddic WR, Bedard YC, Strawbridge HTG. Medullary carcinoma of the thyroid in fine needle aspiration biopsies. Am J Clin Pathol 1984;82(5):552-8.

[10] Boey J, Hsu C, Collins RJ. False negative errors in fine needle aspiration biopsy of dominant thyroid nodules a prospective follow-up study. World J Surg 1986;10(4):623-30.

[11] Tabaqchali MA, Hanson JM, Johnson SJ, et al. Thyroid aspiration cytology in Newcastle: a six year cytology/histology correlation study. Ann R Coll Surg Engl 2000;82(3):149-55.

[12] Piromalli D, Martelli G, Del Prato I, et al. The role of fine needle aspiration in the diagnosis of thyroid nodules. Analysis of 795 consecutive cases. Journal of Surgical Oncology 1992;50(4):247-50.

[13] Agarwal S. Diagnostic accuracy and role of fine needle aspiration cytology in management of thyroid nodules. Journal of Surgical Oncology 1995;58(3):168-72.

[14] Afroze N, Kayani M, Hasan SH. Role of fine needle aspiration cytology in the diagnosis of palpable thyroid lesions. Indian Journal of Pathology Microbiology 2002;45(3):241-6.

[15] Mitra RB, Pathak S, Guha D, et al. Fine needle aspiration cytology of thyroid gland and histopathological correlation--revisited. Journal of the Indian Medical Association 2002;100(6):382-4.

[16] Lowhagen T, Sprenger E. Cytological presentation of thyroid tumours in aspiration bioipsy smears. A review of 60 cases. Acta Cytol 1974;18(3):192-7.

[17] Ramacciotti CE, Pretorius HT, Chu EW, et al. Diagnostic accuracy and use of aspiration biopsy in the management of thyroid nodules. Arch Intern Med 1984;144(6):1169-73.

[18] Siverman JF, West RL, Finley JL, et al. Fine needle aspiration versus large-needle biopsy or cutting biopsy in evaluation of thyroid nodules. Diagn Cytopathol 1986;2(1):25-30.

[19] Altavilla G, Pascale M, Nenci I. Fine needle aspiration cytology of thyroid gland diseases. Acta Cytol 1990;34(2):251-6. 